\title{
Similar long-term outcome for arterial myocardial revascularization performed after or within the first seven day of acute myocardial infarction
}

\author{
Nachum Nesher ${ }^{1,2}$, Rephael Mohr ${ }^{1,2}$, Zvi Raviv ${ }^{1,2}$, Amir Ganiel $^{1,2}$, Yanay Ben-Gal ${ }^{1,2}$, Yosef Paz $^{1,2}$, \\ Amir Kramer $^{1,2}$, Dmitry Pevni ${ }^{1,2}$, Benjamin Medalion ${ }^{2,3}$ \\ ${ }^{1}$ Department of Cardiothoracic Surgery, Tel Aviv Sourasky Medical Center, Tel Aviv, Israel; nesher61@gmail.com \\ ${ }^{2}$ Sackler Faculty of Medicine, Tel Aviv University, Tel Aviv, Israel \\ ${ }^{3}$ Department of Cardiothoracic Surgery, Rabin Medical Center, Petach Tikva, Israel
}

Received 18 June 2013; revised 18 July 2013; accepted 15 August 2013

Copyright (C) 2013 Nachum Nesher et al. This is an open access article distributed under the Creative Commons Attribution License, which permits unrestricted use, distribution, and reproduction in any medium, provided the original work is properly cited.

\section{ABSTRACT}

The current practice of myocardial revascularization for acute myocardial infarction (MI) is primary percutaneous intervention $(\mathrm{PCl})$. Surgical revascularization ("bypass") is reserved for patients unsuitable for $\mathrm{PCl}$. The purpose of this report is to describe the long-term outcome of acute MI patients who underwent left-sided arterial revascularization (left anterior descending and circumflex arteries) before $\mathrm{PCl}$ was adopted as the preferred treatment for this subset of patients. Between 1996 and 2002, 434 consecutive patients in our center underwent myocardial revascularization for recent $\mathrm{MI}$ using the composite T-graft technique (381 bilateral internal thoracic arteries and $\mathbf{5 3}$ single internal thoracic artery and radial arteries). Two-hundred and seventy-six patients were operated on within seven days of an acute MI (Group A) and the remaining 158 patients were operated on after the $7^{\text {th }}$ day since an acute MI (Group B). Group A had significantly increased operative mortality (6.5\% vs $1.3 \%$ for Group $B, P=0.012$ ). Surgery performed within the first week of an acute MI was also found to be a significant predictor of early mortality in multivariate logistic regression analysis (O.R. 10.31; 95\% C.I. 1.32 - 83.30, $P=$ 0.026 ). The mean follow-up was $10.6 \pm 5.2$ years. The Kaplan Meier 10-year survival of the two groups, however, was similar $(65.6 \pm 2.9$ Group A vs $64.6 \pm 3.8$ Group $B, P=0.953$ ), and assignment to Group A was not an independent predictor of decreased survival $(P=0.395$, Cox model). When using arterial grafts for myocardial revascularization, the long-term outcome of pa- tients operated on during the first 7 days of acute MI is not worse than that of patients operated on after more than 7 days, despite their increased operative mortality.

Keywords: Acute Myocardial Infarct; Coronary Artery Bypass Graft Surgery; Urgent

\section{INTRODUCTION}

The long time required to re-perfuse myocardial infarction (MI) patients with surgery, and the efficiency of primary percutaneous intervention (PCI) and fibrinolysis in restoring myocardial blood supply, have caused coronary artery bypass grafting (CABG) to be uncommonly used today as the first line reperfusion strategy for patients with acute MI [1].

Between 1996-2002, arterial grafting of the left coronary system (left anterior descending [LAD] and circumflex arteries) was our preferred method of myocardial revascularization for patients with left main coronary artery or multi-vessel disease because of the better longterm survival associated with this technique compared to single mammary and venous graft [2].

Various strategies have been developed for left-sided revascularization. One popular technique which enables complete arterial revascularization of the left arterial system is the composite T-graft [3]. Mid-and long-term outcomes of patients undergoing bilateral internal thoracic artery (BITA) grafting with composite T-grafts are similar to those of patients undergoing BITA grafting using only in-situ grafts [4]. The comparatively decreased long-term patency of saphenous vein grafts (SVGs) has led to the introduction of other arterial conduits (among them the radial artery [RA]) into clinical 
practice in the belief that the long-term patency will be better than that provided by SVGs [5].

The purpose of this report was to describe the early and long-term surgical results of arterial grafting for a subset of patients who underwent recent MI (3 months).

We also compared the long-term outcome between patients operated on during the first week after an MI and those who were operated on more than one week after an MI.

\section{PATIENTS AND METHODS}

This retrospective review of medical records and the use of telephone questionnaires for obtaining follow-up information were approved by the institutional Review Board of the Tel-Aviv Medical Center. Informed consent was waived. Between 1996 and 2002, 434 consecutive patients with multi-vessel coronary artery disease (CAD) underwent left-sided arterial revascularization using the composite T-graft technique in our medical center within 3 months of acute MI [6]. Two-hundred and seventy-six of these patients were operated on within seven days since undergoing an acute MI (Group A). The remaining 158 underwent surgery after the $7^{\text {th }}$ day of an acute MI (Group B). One internal thoracic artery (ITA) was attached end-to-side to the other ITA (mostly the right ITA to the left ITA) in 381 patients. In the remaining 53 patients, the RA was connected end-to-side to the left ITA. Selection of a bilateral ITA approach versus a single ITA and an RA approach was mainly according to the surgeon's preference. There was a tendency not to use bilateral ITAs in patients with increased risk for sternal wound complications, such as elderly patients, patients with chronic obstructive pulmonary disease (COPD) or females with diabetes and/or obesity [7]. In addition, a composite T-graft with an RA was used only when the target coronary vessel stenosis was greater than $80 \%$ $90 \%[5,8]$. Seventy-four (17\%) of the patients were operated on without extracorporeal circulation (off-pump coronary artery bypass [OPCAB]). All ITAs were harvested as skeletonized vessels and were used preferentially for left-sided revascularization. Revascularization of the right system was performed with SVGs, with the right gastroepiploic artery, or with the distal end of the T-graft (radial artery or right ITA).

We treated all coronary artery bypass grafting (CABG) patients with a high-dose intravenous infusion of isosorbide dinitrate (Isoket; Schwarz Pharma AG, Monheim, Germany) 4 to $20 \mathrm{mg} / \mathrm{h}$ during the first 24 to 48 hours postoperatively. From the second postoperative day, patients whose RA and right gastroepiploic artery were used for grafting were treated with oral calcium channel blockers (diltiazem) $90 \mathrm{mg}$ to $180 \mathrm{mg}$ daily. All CABG and PCI patients were permanently prescribed aspirin $100 \mathrm{mg}$ daily, as well as statins.

\subsection{Definitions and Data Collection}

Patients' data were analyzed according to American College of Cardiology/American Heart Association clinical data standards [9]. Diabetic patients included individuals who were being treated with insulin or oral hypoglycemic agents. A periprocedural MI was defined as the post-procedure appearance of new Q waves or an ST segment elevation of more than $2 \mathrm{~mm}$ on an electrocardiograph, accompanied by a creatine phosphokinasemyocardial band greater than $50 \mathrm{mU} / \mathrm{mL}$ with or without a new regional wall motion abnormality. An "emergency" operation was defined as one performed within 24 hours of cardiac catheterization.

\subsection{Statistical Analysis}

Data are expressed as mean $\pm \mathrm{SD}$ or proportions, as appropriate. Continuous variables were compared using the $t$ test, and categorical variables were compared by using the $\chi^{2}$ or Fisher exact tests, as appropriate. $\mathrm{P}<0.05$ is considered as significant. Multivariable logistic regression analysis was used to indentify predictors of early (30 day) perioperative mortality. Follow-up information was obtained

\section{RESULTS}

Preoperative patient characteristics were similar between the two study groups (Table 1). Patients in Group B were older, while several risk factors, such as emergency operation, preoperative use of intra-aortic balloon pump (IABP), and repeat operations, were more prevalent in Group A. The Euroscore of the two groups was similar $(7.15 \pm 3.3$ vs $7.2 \pm 3.5, \mathrm{P}=\mathrm{NS})$. The extent of coronary artery involvement was not significantly different between the groups, however there was a trend for an increased prevalence of left main coronary artery disease in Group A $(\mathrm{P}=0.08)$.

Table 2 describes details of the surgical techniques used in the two groups. The only significant difference was the increased use of OPCAB in Group B. The early mortality (30 days) rate of the patients in Group A was significantly higher $(6.5 \%$ vs. $1.3 \%$ for Group B, P = 0.012). Both Group A and Group B had similar occurrences of early postoperative complications, such as postoperative deep sternal wound infection $(2.9 \%$ vs $1.9 \%$, respectively $\mathrm{P}=0.524)$, postoperative stroke $(2.5 \%$ vs $0.6 \%, \mathrm{P}=0.156)$ and perioperative $\mathrm{MI}(1.4 \%$ vs $0 \%, \mathrm{P}=0.128)$.

A multivariable logistic regression model revealed that surgery that had been performed during the first week after an MI (Group A) was significantly associated with an increased risk of operative mortality (O.R. 10.31; 95\% C.I. $1.32-83.30, \mathrm{P}=0.026)$. Other predictors of increased mortality were the preoperative use of IABP 
Table 1. Patients characteristics.

\begin{tabular}{cccc}
\hline & $\begin{array}{c}\text { Group A } \\
\mathbf{N}=\mathbf{2 7 6}\end{array}$ & $\begin{array}{c}\text { Group B } \\
\mathbf{N}=\mathbf{1 5 8}\end{array}$ & P-value \\
\hline Age, y 65 & $112(45.9 \%)$ & $61(44.5 \%)$ & 0.03 \\
$65-75$ & $101(41.1 \%)$ & $45(32.8 \%)$ & \\
75 & $31(12.7 \%)$ & $31(22.6 \%)$ & \\
Female & $68(24.6 \%)$ & $47(29.7 \%)$ & 0.246 \\
NIDDM & $92(33.3 \%)$ & $60(38 \%)$ & 0.329 \\
IDDM & $10(3.6 \%)$ & $3(1.9 \%)$ & 0.311 \\
COPD & $23(8.3 \%)$ & $12(7.6 \%)$ & 0.786 \\
CHF & $104(37.7 \%)$ & $55(34.8 \%)$ & 0.550 \\
PVD & $60(21.7 \%)$ & $40(25.3 \%)$ & 0.394 \\
EF $\leq 30 \%$ & $34(12.3 \%)$ & $12(7.6 \%)$ & 0.124 \\
Unstable angina & $110(39.9 \%)$ & $69(43.7 \%)$ & 0.437 \\
Emergency op. & $79(28.6 \%)$ & $20(12.7 \%)$ & $<0.001$ \\
Repeat op. & $11(4 \%)$ & $1(0.6 \%)$ & 0.040 \\
CRF (Cr > 1.8) & $23(5.3 \%)$ & $20(12.7 \%)$ & 0.147 \\
Preop. IABP & $33(12 \%)$ & $9(5.7 \%)$ & 0.034 \\
Left main & $65(23.6 \%)$ & $26(16.5 \%)$ & 0.081 \\
3VD & $210(76.1 \%)$ & $112(70.95)$ & 0.121 \\
\hline
\end{tabular}

Group A: arterial myocardial revascularization within 7 days of acute myocardial infarction; Group B: arterial myocardial revascularization $>7$ days of acute myocardial infarction; NIDDM: non-insulin dependent diabetes mellitus; IDDM: insulin-treated diabetes mellitus; COPD: chronic obstructive pulmonary disease; CHF: congestive heart failure; PVD: peripheral vascular disease; Left main: left main coronary artery disease; VD: vessel disease; EF: ejection fraction; op.: operation; CRF: chronic renal failure; Cr: creatinine; Preop.: preoperative; IABD: intra-aortic balloon pump.

Table 2. Surgical data.

\begin{tabular}{cccc}
\hline & $\begin{array}{c}\text { Group A } \\
\mathbf{N}=\mathbf{2 7 6}\end{array}$ & $\begin{array}{c}\text { Group B } \\
\mathbf{N = 1 5 8}\end{array}$ & P-value \\
\hline OPCAB & $37(13.45 \%)$ & $37(23.4 \%)$ & 0.008 \\
Sequential grafting & $186(69.7 \%)$ & $96(66.7 \%)$ & 0.532 \\
Use of SVG & $48(18 \%)$ & $18(12.5 \%)$ & 0.149 \\
Use of right GEAs & $44(16.5 \%)$ & $27(18.8 \%)$ & 0.561 \\
$\geq 3$ grafts & $205(84 \%)$ & $103(75.2 \%)$ & 0.360 \\
Use of BITA & $244(88.4 \%)$ & $137(86.7 \%)$ & 0.603 \\
\hline
\end{tabular}

OPCAB: off pump coronary artery bypass grafting; SVG: saphenous vein graft; GEA: gastroepiploic artery; BITA: bilateral internal thoracic artery

(O.R. 3.571, 95\% C.I. $1.098-11.628, \mathrm{P}=0.034)$ and peripheral vascular disease (PVD) (O.R. 2.933, 95\% C.I. 1.019 - 8.474, $\mathrm{P}=0.046$ ).

The mean follow-up for the entire cohort was $10.6 \pm$ 5.2 years. The Kaplan Meier 10-year survival of the two groups was almost identical $(65.6 \% \pm 2.9 \%$ and $64.6 \% \pm$ $3.8 \%$ for Groups $\mathrm{A}$ and $\mathrm{B}$, respectively, $\mathrm{P}=0.953 \mathrm{Log}$ Rank test) (Figure 1). Assignment to Group A did not emerge as an independent predictor of late mortality $(\mathrm{P}=$ 0.395, Cox Model). Independent predictors of decreased survival were age (H.R. 1.067, 95\% C.I. 1.050 - 1.087),

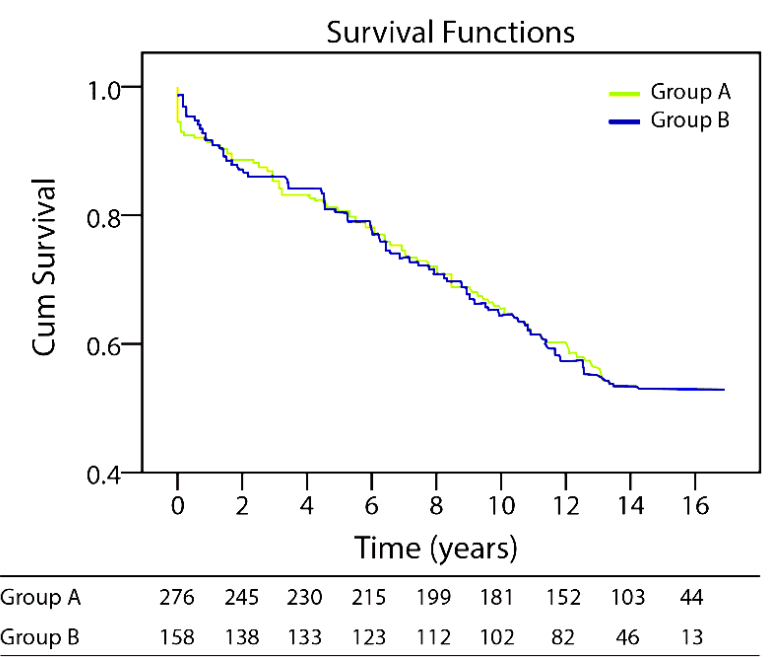

Figure 1. Kaplan-Meier survival curves according to timing of surgery after myocardial infarction (Group A vs Group B).

diabetes mellitus (H.R. 1.464, 95\% C.I. 1.107 - 1.996, P $=0.016$ ), IABP (H.R. 2.652, 95\% C.I. $1.600-4.386, \mathrm{P}<$ 0.001), and PVD (H.R. 1.531, 95\% C.I. 1.077 - 2.179). Surgery performed without extracorporeal circulation (OPCAB) had a significantly better long-term adjusted survival (H.R. $0.491,95 \%$ C.I. $0.278-0.867, \mathrm{P}=0.014$, Figure 2).

\section{DISCUSSION}

This retrospective report evaluated the long-term clinical outcome of coronary bypass grafting $(\mathrm{CABG})$ in patients with multi-vessel disease, who underwent arterial revascularization within 3 months of an acute MI [6]. A series of patients in whom arterial grafting (two ITAs or one ITA and an RA) was performed during the first week after an acute MI (Group A) was compared to the patients who were operated on after the $7^{\text {th }}$ day of an acute MI (Group B). The increased operative mortality observed in Group A is probably related to differences between groups in the occurrence of known risk factors, such as critical preoperative state (e.g., preoperative IABP), emergency operation and repeat operation.

Our study results showed an increased operative mortality among patients operated during the first week after an acute MI. However, after a mean follow-up of 10.6 years, their long-term survival (Kaplan-Meier and Cox adjusted) was not inferior to that of patients who underwent arterial grafting later than the first week after an acute MI.

Our group had previously reported a significantly lower operative mortality for patients undergoing OP$\mathrm{CAB}$ compared to standard on-pump CABG within the first 48 hours after an acute MI [10]. However, a long-term follow up (5 years) showed no survival benefit for OPCAB surgery [10]. In contrast to those findings, 


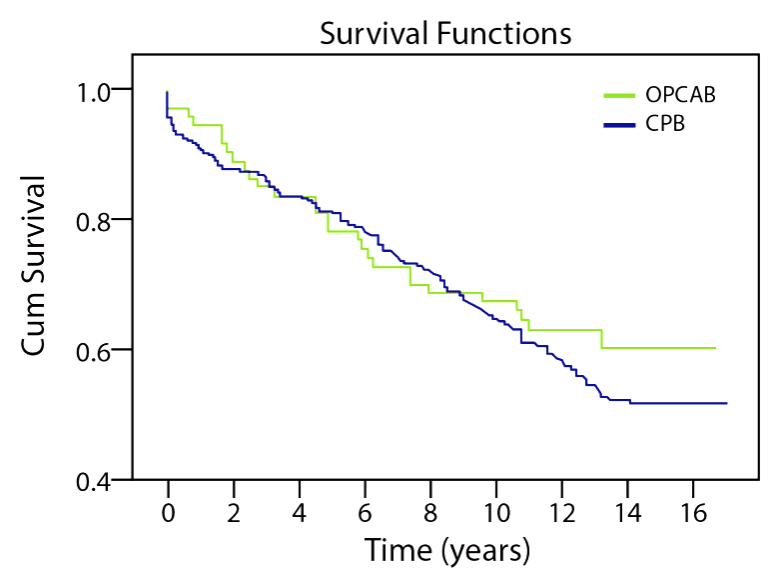

Figure 2. Cox adjusted curves according to surgical technique (off-pump coronary artery bypass vs surgery with cardiopulmonary bypass).

the current report with a longer follow-up period revealed better long-term adjusted survival with OPCAB surgery. This observation may be related to the use of multiple arterial conduits (mainly double ITAs) and more complete revascularization in the OPCABs of the current study patients.

The widespread application of early PCI or fibrinolysis for acute MI patients led to a significant decrease in the number of emergency CABG procedures for revascularization. CABG is currently reserved mostly for patients after an unsuccessful or complicated PCI [11,12], and for unstable patients with left main coronary artery or severe three-vessel disease who cannot be safely treated with PCI [13]. In addition, ACC/AHA guidelines for $\mathrm{CABG}$ or PCI recommend surgery rather than PCI to some MI patients with ST elevation MIs present later (more than 12 hours) and are asymptomatic (Management of this subset of patients is similar to that of patients with stable CAD).

A similar management is recommended for post-PCI patients who develop recurrent angina or re-infarction [14]. The long-term results of the current report suggest that arterial grafting is not only the preferred approach for patients with stable angina, but that it is also suitable for patients operated on during the first week after an acute MI.

\subsection{Limitations}

This is a retrospective study. Supplementary angiographic data that could have strongly supported the message conveyed by clinical observations were not available. A complete follow-up of major adverse cardiovascular events (MACE) was not available in many patients and therefore MACE values were not included among the results.

\subsection{Conclusion}

Surgical revascularization ("bypass") is reserved for acute MI patients who could benefit from but are unsuitable for PCI for whatever reason. The operative mortality is higher when arterial grafts are used for myocardial revascularization in patients who are operated on within the first seven days after an acute MI (including emergency and IABP-supported patients). The long-term outcome of these patients, however, is similar to that of patients with acute MI who are operated on later than seven days post-acute MI.

\section{ACKNOWLEDGEMENTS}

The authors thank Esther Eshkol for editorial assistance.

Dmitry Pevni and Benjamin Medalion contributed equally to this work.

\section{REFERENCES}

[1] Stone, G.W., Brodie, B.R., Griffin, J.J., Grines, L., Boura, J., O’Neill, W.W. and Grines, C.L. (2000) Role of cardiac surgery in the hospital phase management of patients treated with primary angioplasty for acute myocardial infarction. American Journal of Cardiology, 85, 1292-1296. http://dx.doi.org/10.1016/S0002-9149(00)00758-X

[2] Lytle, B.W., Blackstone, E.H., Loop, F.D., Houghtling, P.L., Arnold, J.H., Akhrass, R., et al. (1999) Two internal thoracic arteries are better than one. Journal of Thoracic and Cardiovascular Surgery, 117, 855-872. http://dx.doi.org/10.1016/S0022-5223(99)70365-X

[3] Tector, A.J., Amundsen, S., Schmahl, T.M., Kress, D.C. and Peter, M. (1994) Total revascularization with T-grafts. Annals of Thoracic Surgery, 57, 8-9. http://dx.doi.org/10.1016/0003-4975(94)90361-1

[4] Lev-Ran, O., Paz, Y., Pevni, D., Kramer, A., Shapira, I., Locker, C., et al. (2002) Bilateral internal thoracic artery grafting: Midterm results of composite versus in situ crossover graft. Annals of Thoracic Surgery, 74, 704-710. http://dx.doi.org/10.1016/S0003-4975(02)03791-8

[5] Moran, S.V., Baeza, R., Guarda, E., Zalaquett, R., Irarrazaval, M.J., Marchant, E., et al. (2001) Predictors of radial artery patency for coronary bypass operations. Annals of Thoracic Surgery, 72, 1552-1556. http://dx.doi.org/10.1016/S0003-4975(01)03090-9

[6] Roques, F., Michel, P., Goldstone, A.R. and Nashef, S.A. (2003) The logistic Euroscore. European Heart Journal, 24, 882-993. http://dx.doi.org/10.1016/S0195-668X(02)00799-6

[7] Matsa, M., Paz, Y., Gurevitch, J., Shapira, I., Kramer, A., Pevny, D., et al. (2001) Bilateral skeletonized internal thoracic artery grafts in patients with diabetes mellitus. Journal of Thoracic and Cardiovascular Surgery, 121, 668-674. http://dx.doi.org/10.1067/mtc.2001.112824

[8] Pevni, D., Hertz, I., Medalion, B., Kramer, A., Paz, Y., Uretzky, G., et al. (2007) Angiographic evidence for reduced graft patency due to competitive flow in composite 
arterial T-grafts. Journal of Thoracic and Cardiovascular Surgery, 133, 1220-1225.

http://dx.doi.org/10.1016/i.jtcvs.2006.07.060

[9] Radford, M.J., Arnold, J.M., Bennett, S.J., et al. (2005) ACC/AHA key data elements and definitions for measuring the clinical management and outcomes of patients with chronic heart failure: A report of the American College of Cardiology/American Heart Association Task Force on Clinical Data Standards (Writing Committee to Develop Heart Failure Clinical Data Standards). Circulation, 112, 1888-1916.

http://dx.doi.org/10.1161/CIRCULATIONAHA.105.1700 $\underline{73}$

[10] Locker, C., Mohr, R., Paz, Y., Kramer, A., Lev-Ran, O., Pevni D. and Shapira, I. (2003) Myocardial revasculariztion for acute myocardial infarction: benefits and drawbacks of avoiding cardiopulmonary bypass. Annals of Thoracic Surgery, 76, 771-776. http://dx.doi.org/10.1016/S0003-4975(03)00732-X

[11] Buffet, P., Danchin, N., Villemot, J.P., et al. (1991) Early and long-term outcome after emergency coronary artery bypass surgery after failed coronary angioplasty. Circulation, 84, III254-III259.
[12] Chiu, F.C., Chang, S.N., Lin, J.W., et al. (2009) Coronary artery bypass graft surgery provides better survival in patients with acute coronary syndrome or ST-segment elevation myocardial infarction experiencing cardiogenic shock after percutaneous coronary intervention: A propensity score analysis. Journal of Thoracic and Cardiovascular Surgery, 138, 1326-1330.

http://dx.doi.org/10.1016/j.jtcvs.2009.03.038

[13] Levine, G.N., Bates, E.R., Blankenship, J.C., et al. (2011) 2011 ACCF/AHA/SCAI Guideline for Percutaneous Coronary Intervention: A report of the American College of Cardiology Foundation/American Heart Association Task Force on Practice Guidelines and the Society for Cardiovascular Angiography and Interventions. Circulation, 124, Article ID: e574. http://dx.doi.org/10.1161/CIR.0b013e31823ba622

[14] Hillis, L.D., Smith, P.K., Anderson, J.L., et al. (2011) 2011 ACCF/AHA Guideline for Coronary Artery Bypass Graft Surgery: Executive summary: A report of the American College of Cardiology Foundation/American Heart Association Task Force on Practice Guidelines. Circulation, 124, 2610-2642.

http://dx.doi.org/10.1161/CIR.0b013e31823b5fee

COPD: chronic obstructive pulmonary disease

$\mathrm{CHF}$ : congestive heart failure

PVD: peripheral vascular disease

CRF: chronic renal failure

IABP: intra-aortic balloon pump

LM: left main coronary artery

3VD: 3-vessel disease

EF: ejection fraction

Emergency: surgery within 24 hours of coronary angiography 